\title{
BesPRECHUNGen \\ What happens in language loss?
}

Kehayov, Petar. 2017. The fate of mood and modality in language death. Berlin: Walter de Gruyter. $385 \mathrm{pp}$.

Loss of individual languages is occurring rapidly and around the world. There are numerous casespecific changes and local stories which strongly affect the current state of most languages belonging to the Finnic branch of the Uralic language family. This is the starting point of Petar Kehayov's fascinating work on language change, obsolescent communities and the language choices of minority-language speakers. The book is a thorough study of a theoretically motivated issue, namely how last speakers of individual languages and speech communities deal with morphologically complex features that carry specific grammatical functions.

Unlike many other linguistic studies, this book draws on exclusively its own data emphasizing its up-to-date nature. The data are freshly collected and two illustrative examples are attached to the published study. A questionnaire has been used as the primary method for more specific purposes, namely the analysis of changes in mood and modality. Compared to primary data drawn from colloquial speech, elicitation and translated clauses run certain risks, most notably the unexpected influence of the source language on the recipient language. However, this is exactly what the author is looking for. More importantly, his previous knowledge of the Finnic languages, and the various types of contacts they have had with other languages, is so comprehensive that the result is impressive. The treatment of individual aspects is careful and precise, and these aspects actually amount to much more than the title alone suggests.

The book is concise, with no superfluous elements included, and it consists of ten chapters. The theoretical foundations of the study are carefully introduced as both language death and mood and modality are conceptually clarified, separately in Chapters 2-3, and together in Chapter 4. Here, probabilistic hierarchies between categories are introduced; for instance, standard questions about 
the relationship between mood and tense but also hierarchies between different modal categories, which have been less thoroughly analyzed in earlier studies. The author shows that, actually, this kind of unbalanced language-contact situation can reveal subtle shifts in modality. After introducing in Chapter 5 the languages on which the work focuses and the methods of inquiry in Chapter 6, the author finally devotes the biggest part, altogether 210 pages, to substantial questions in Chapters 7-9. This is a linguistic tour de force as Petar Kehayov treats the core categories in a multifaceted way. Mood and modality in language death in fact involve numerous other verbal categories starting with tense, person and number, and verbal semantics. Chapter 10 concludes the work.

The four severely endangered Finnic varieties in focus are Central Lude, Ingrian, Votic and Eastern Seto, the last a variety of South Estonian. All of these varieties are or used to be spoken in Russia until very recently and their speech communities have all undergone a rapid language shift over the 2oth century. The author has personally worked with speakers of each of these Finnic varieties and observed how language contact with Russian has influenced the speech of individuals and what kind of structural and functional changes are manifested in more limited constructions. Given how closely related the four selected varieties are, one might assume that Russian influence in modal constructions is quite uniform. However, this is not the case, which emphasizes the importance of subtle languagespecific characteristics. The author succeeds in pointing out finegrained differences in morphological changes, the amalgamation of morphosyntactic patterns and even mechanisms of code-switching along the border zone of Finnic and Russian.

Petar Kehayov's book is a very welcome contribution to research on language endangerment, erosion of grammatical categories, and the ultimate loss of minority languages. Every detail is clearly explained, every conclusion is based on a profound understanding of all languages involved in the contact. It answers a number of detailed questions and outlines the big picture on the basis of a strong typological foundation. It opens a new perspective for research into both endangered Uralic languages and mechanisms of language contact at the final stage of language loss.

Riho Grünthal 